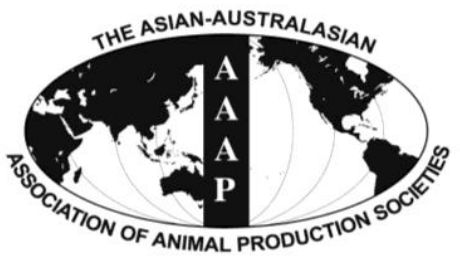

Asian-Aust. J. Anim. Sci.

Vol. 25, No. 9 : 1322 - 1328

September 2012

www.ajas.info

http://dx.doi.org/10.5713/ajas.2012.12023

\title{
Increases of Antibiotic Resistance in Excessive Use of Antibiotics in Smallholder Dairy Farms in Northern Thailand
}

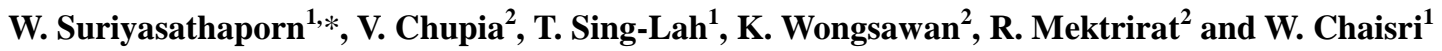 \\ ${ }^{1}$ Department of Food Animal Clinics, ${ }^{2}$ Department of Veterinary Bioscience and Veterinary Public Health, \\ Faculty of Veterinary Medicine, Chiang Mai University, \\ Chiang Mai 50100, Thailand
}

\begin{abstract}
Antibiotic resistance patterns of bacterial isolates from both quarter teat-tip swabs and their quarter milk samples were evaluated in smallholder dairy farms in northern Thailand with excessive use of antibiotics (HIGH) compared with normal use (NORM). Results from teat-tip swab samples showed that the percentage of Bacillus spp. resistance to overall antibiotics was significantly lower in the NORM group than that of the HIGH group, whereas, the resistance percentage of coagulase-negative staphylococci in the NORM group was higher than that of the HIGH one. The overall mastitis-causing bacteria isolated from milk samples were environmental streptococci (13.8\%), coagulase-negative staphylococci (9.9\%), Staphylococcus aureus (5.4\%), and Corynebacterium bovis (4.5\%). Both staphylococci and streptococci had significantly higher percentages of resistance to cloxacillin and oxacillin in the HIGH group when compared to the NORM one. An occurrence of vancomycin-resistant bacteria was also observed in the HIGH group. In conclusion, the smallholder dairy farms with excessive use of antibiotics had a higher probability of antibiotic-resistant pattern than the farms with normal use. (Key Words: Antibiotic Resistance, Environment, Mastitis, Cow, Bacteria, Dairy Farm)
\end{abstract}

\section{INTRODUCTION}

In Southeast Asia, smallholder dairying has provided good income for crop farmers in mixed farming systems. With further improvement in productivity and reduction in production costs, Chantalakhana and Skunmun (2002) believe that smallholder dairying in this region can become a very sound and sustainable enterprise. Thailand has the fastest growing dairy industry in tropical Asia, with $610 \%$ more milk production in 2006 than in the period 1990/92; a growth rate of $38 \%$ per annum (Moran, 2009). In parallel with this rapid development, antibiotics are increasingly utilized in Thailand's dairy industries. Based on a report from the Thai Drug Control Division, the number of animal drugs produced in Thailand increased 3.9 times between 1996 and 2005 (Thai-Drug-Control-Division, 2009). The use of these antibiotics in animals and their accumulation in humans could lead to bacterial resistance, which would shorten the usable life of human medicines.

Antibiotics in dairy cattle are primarily used to treat or

\footnotetext{
* Corresponding Author: W. Suriyasathaporn. Tel: +66-53-948 023, Fax: +66-53-274710, E-mail: Suriyasathaporn@ hotmail.com Submitted Jan. 10, 2012; Accepted Apr. 16, 2012; Revised May 7, 2012
}

prevent diseases and, hence, increase milk production and/or improve feed efficiency. No antibiotic is completely effective at eliminating all target bacteria within their complex microbial communities, which are frequently encountered within agricultural systems. Consequently, it is inevitable that antibiotic therapy will eventually reduce the number of antibiotic-susceptible strains and promote the development of antibiotic-resistant strains (McAllister et al., 2001). Studies in Thailand have found antibiotic resistance in some bacteria, especially Salmonella spp. isolated from food animals and humans (Boonmar et al., 1998; Hanson et al., 2002), including resistance to relatively new antibiotic agents such as azithromycin and ciprofloxacin (Isenbarger et al., 2002).

The use of antibiotics in animals in Thailand has been regulated by the Department of Livestock Development (DLD), Ministry of Agriculture and Cooperation, Thailand, since 2003. Nowadays, Thailand has successfully adopted developed country standards into a developing country framework since knowing that Thai poultry and seafood is inspected at EU customs. However, not all farms in the country have met these new requirements for antibiotic drug use. One tool for controlling antibiotic use is the 
certification of farm standards by the DLD. All antibiotic use in the standard dairy farms must be authorized by DLD trained and registered official-farm-advisor veterinarians, and recorded. Although the antibiotics used is an important component of a preventive and treatment program, the final decision for their use is taken by the farm owners themselves based on their experience and economic situation. The different frequency of antibiotic use might result in differences in the antibiotic resistance of bacteria in either the udder or environment. Therefore, the objective of this study was to identify the antibiotic resistance of pathogens isolated from either quarter milk or the environment.

\section{MATERIALS AND METHODS}

\section{Farm selection and study design}

This study was performed during 15th to 30th March 2008. Eighteen smallholder dairy farms (a farm with $>20$ milking cows) which were members of Mae Wang Dairy cooperative, Chiang Mai Province, Thailand, were included in the study. To control the difference of location, all farms were situated within a $5-\mathrm{km}$ radius. All the farms had been certified as standard DLD farms for at least 2 years, and were advised by an official-farm-advisor veterinarian from their cooperative. All antibiotic use had been authorized by the veterinarian and recorded as a regulation of certified standard farms. All the farms had been in the herd health management program, including reproductive management, mastitis control program and data collection, for at least 6 months. The mastitis control program of their cooperative included monthly somatic cell count testing at farm and cow levels, decision making on the treatment of clinical and subclinical mastitis cows, regular milking machine instrument checking, price penalty on high bulk somatic cell count, and a fine of 20 times the cost of milk revenue when the milk sold was contaminated with antibiotics. Most cows were crossbred Holstein Friesian that were in free stall barns and milked twice daily. Bucket-type milking machines were used in all farms, with an average of 6 cows/milking unit.

The farms were separated into 2 groups based on their antibiotic use records by the authorized veterinarian. In general, Thai dairy farmers have an only routine use of antibiotic for antibiotic dry cow therapy, and most cows will experience once with antibiotic treatment during lactation. Therefore, most cows were received approximately 2 times in lactation with taking about 1 yr. From annual antibiotic use records, an annual average of antibiotic use in a farm was calculated from individual use, and was used to determine the farm group variable. The farm groups comprised i) normal use (NORM), being no more than 2 times/cow/yr of antibiotic use, and ii) excessive use (HIGH), being more than 2 times/cow/yr. Milk samples were collected from chronic subclinical mastitis cows identified by $<200,000$ cells/cc of the last two somatic cell count (SCC) measurements or clinical mastitis cows at sample collection date. Milk samples, which were separated into quarters of subclinical mastitis cows, were aseptically collected. Systematic random sampling of cows selected with an odd-number was used to collect swab samples at the rear-right teat tip areas. Sterile cotton buds soaked in $0.9 \%$ normal saline were used to swab the $1 \times 1 \mathrm{~cm}^{2}$ area of the teat tips, and collect transport media. Samples were immediately transported to the milk quality laboratory of Faculty of Veterinary Medicine, Chiang Mai University.

\section{Bacterial identification}

All milk samples were cultured on trypticase soy agar containing $5 \%$ bovine calf blood and incubated at $37^{\circ} \mathrm{C}$ for 48 h. The colonies presented were examined microbiologically according to standard procedures of the National Mastitis Council (Harmon et al., 1990). Criteria were made for the diagnosis of pathogens based on bacterial morphology, gram staining and biochemical tests. Distinguishing streptococci and staphylococci was carried out by the catalase test. Bacteria exhibiting a catalase positive reaction were examined further by the coagulase test to differentiate the potential of Staph. aureus from the usual coagulase-negative staphylococci (CNS), while catalase negative bacteria were tested with the CAMP reaction, esculin hydrolysis and sugar fermentation tests to distinguish Streptococcus spp. Grown gram-negative bacteria were also determined by using biochemical characteristics including, triple sugar iron agar, and motility indole lysine, citrate utilization and urea hydrolysis tests.

\section{Antibiotic susceptibility testing}

Antibiotic susceptibility of the isolates was determined by the agar disc diffusion method according to the standard National Mastitis Council guideline (NMC, 1999). The antibiotics used included tetracycline $(30 \mu \mathrm{g})$, oxacillin (1 $\mu \mathrm{g})$, cloxacillin $(5 \mu \mathrm{g})$, cephalexin $(30 \mu \mathrm{g})$, vancomycin (30 $\mu \mathrm{g})$, erythromycin $(15 \mu \mathrm{g})$, gentamycin $(10 \mu \mathrm{g})$, and neomycin $(30 \mu \mathrm{g})$. Isolates categorized as susceptible or resistant (the latter including both 'intermediate' and "resistant" isolates) were in accordance with the methods and criteria described by the National Committee for Clinical Laboratory Standards (NCCLS, 2002).

\section{Statistical analysis}

Data on the distribution of bacterial isolates and antibiotic resistance were described by frequency and percentages. Comparisons of bacterial isolates and antibiotic susceptibilities were performed among the farm groups by Fisher's Exact Chi-square tests. Significant levels 
Table 1. Characteristics of farms with different antibiotics use: i) normal use (NORM), being no more than 2 times/cow/yr of antibiotic use, and ii) excessive use (HIGH), being more than 2 times/cow/yr

\begin{tabular}{|c|c|c|c|c|}
\hline & NORM & HIGH & Statistic value & p-value \\
\hline \multicolumn{5}{|l|}{ Farm characteristics } \\
\hline Number of farms & 8 & 10 & & \\
\hline Total cows in farms & 110 & 128 & & \\
\hline Average cows per farm & 13.75 & 12.80 & & \\
\hline $\begin{array}{l}\text { Subclinical mastitis prevalence } \\
\text { in the last } 3 \text { months prior to study }\end{array}$ & 0.43 & 0.35 & 4.53 & 0.04 \\
\hline \multicolumn{5}{|l|}{ Cow characteristics (mean \pm SEM) } \\
\hline Average parity & $2.66 \pm 0.23$ & $3.71 \pm 0.34$ & -2.55 & 0.01 \\
\hline Average days in milk (days) & $239 \pm 21.1$ & $173 \pm 15.4$ & 2.31 & 0.02 \\
\hline Geometric mean of somatic cells & 845 & 580 & 1.65 & 0.10 \\
\hline $\begin{array}{l}\text { Geometric mean of somatic cells } \\
\text { in the last } 3 \text { months prior to study }\end{array}$ & 387 & 361 & 0.21 & 0.83 \\
\hline \multicolumn{5}{|l|}{ Sample characteristics } \\
\hline Number of subclinical mastitis cows & 38 & 38 & 0.44 & 0.51 \\
\hline Number of sampling cows & 36 & 37 & & \\
\hline Number of quarter samples & 140 & 147 & & \\
\hline Positive intramammary-infected cows & 23 & 24 & 0.00 & 1.00 \\
\hline Positive intramammary-infected quarters & 50 & 56 & 0.09 & 0.77 \\
\hline Number of swab samples (cows) & 12 & 15 & & \\
\hline
\end{tabular}

were defined at $\mathrm{p}<0.05$.

\section{RESULTS}

The total number of milking cows from 18 smallholder dairy farms was 238 , with an average of 13.22 cows/farms. Farms, cows and sample characteristics were separated into farm groups as described in Table 1. The general characteristics of farms and samples used in both groups were similar; except for the prevalence of subclinical mastitis in the NORM group during the last 3 months prior to study, which was significantly higher than that in the HIGH group. Cow performance in HIGH farms was different to that in NORM ones, including parity, days in milk, and somatic cell counts (Table 1). From 38 subclinical cows in both groups, 2 in the NORM group and 1 in the HIGH one were excluded from experiments because of farm management problems. Four quarters in the NORM group and a quarter in the HIGH one did not function. Cows in the HIGH group had higher average parity and lower average days in milk than those in the NORM group $(\mathrm{p}<0.05)$.

Percentages of antibiotic resistance patterns of Bacillus spp. and CNS of the swap samples from farms with high and low antibiotic use are shown in Table 2. The percentages of all antibiotic resistance in Bacillus spp. were significantly lower in the NORM group (18.2\%) than in the HIGH one $(72.7 \%)$. In contrast, the percentage of CNS

Table 2. Percentages of antibiotic resistant patterns of Bacillus spp. and coagulase-negative staphylococci (CNS) from swab samples of farms with high (HIGH) and normal antibiotic use (NORM)

\begin{tabular}{|c|c|c|c|c|c|c|c|c|c|c|}
\hline \multirow{3}{*}{ Antibiotics } & \multicolumn{4}{|c|}{ Bacillus spp. } & \multirow{3}{*}{$\mathrm{p}$} & \multicolumn{4}{|c|}{ CNS } & \multirow{3}{*}{$\mathrm{p}$} \\
\hline & \multicolumn{2}{|c|}{$\operatorname{NORM}(\mathrm{n}=11)$} & \multicolumn{2}{|c|}{$\mathrm{HIGH}(\mathrm{n}=11)$} & & \multicolumn{2}{|c|}{ NORM $(n=8)$} & \multicolumn{2}{|c|}{ HIGH $(n=26)$} & \\
\hline & $S^{1}$ & $\mathrm{R}^{1}$ & $\mathrm{~S}$ & $\mathrm{R}$ & & $\mathrm{S}$ & $\mathrm{R}$ & $\mathrm{S}$ & $\mathrm{R}$ & \\
\hline Oxytetracyclin & 100.0 & 0.0 & 63.6 & 36.4 & 0.09 & 75.0 & 25.0 & 96.2 & 3.9 & 0.13 \\
\hline Cloxacillin & 100.0 & 0.0 & 63.6 & 36.4 & 0.09 & 75.0 & 25.0 & 84.6 & 15.4 & 0.61 \\
\hline Oxacillin & 100.0 & 0.0 & 72.7 & 27.3 & 0.21 & 75.0 & 25.0 & 84.6 & 15.4 & 0.61 \\
\hline Cephalexine & 90.9 & 9.1 & 90.9 & 9.1 & 1.00 & 87.5 & 12.5 & 96.2 & 3.9 & 0.42 \\
\hline Vancomycin & 100.0 & 0.0 & 90.9 & 9.1 & 1.00 & 100.0 & 0.0 & 96.2 & 3.9 & 1.00 \\
\hline Gentamycin & 90.9 & 9.1 & 81.8 & 18.2 & 1.00 & 87.5 & 12.5 & 100.0 & 0.0 & 0.23 \\
\hline Erythromycin & 100.0 & 0.0 & 81.8 & 18.2 & 0.48 & 87.5 & 12.5 & 96.2 & 3.9 & 0.42 \\
\hline Neomycin & 90.9 & 9.1 & 90.9 & 9.1 & 1.00 & 87.5 & 12.5 & 88.5 & 11.5 & 1.00 \\
\hline All antibiotics ${ }^{\mathrm{a}}$ & 81.8 & 18.2 & 27.3 & 72.7 & 0.03 & 37.5 & 62.5 & 76.9 & 23.1 & 0.08 \\
\hline Resistances $\geq 2$ antibiotics & 90.9 & 9.1 & 54.6 & 45.5 & 0.15 & 75.0 & 25.0 & 80.8 & 19.2 & 1.00 \\
\hline
\end{tabular}

${ }^{1} \mathrm{~S}=$ Susceptible, $\mathrm{R}=$ Resistance. ${ }^{\mathrm{a}}$ Resistant to at least one drug test. 
Table 3. Bacterial isolates from quarter milk samples of subclinical mastitis cows separated into farm groups comprising i) normal use (NORM), being no more than 2 times/cow/yr of antibiotic use, and ii) excessive use (HIGH), being more than 2 times/cow/yr

\begin{tabular}{|c|c|c|c|c|c|c|c|}
\hline & \multicolumn{2}{|c|}{ All } & \multicolumn{2}{|c|}{ NORM } & \multicolumn{2}{|c|}{ HIGH } & \multirow{2}{*}{$p$-value ${ }^{a}$} \\
\hline & $\mathrm{N}$ & Percent & $\mathrm{N}$ & Percent & $\mathrm{N}$ & Percent & \\
\hline Negative sample & 204 & 65.2 & 96 & 62.3 & 108 & 67.9 & 0.34 \\
\hline CNS & 31 & 9.9 & 21 & 13.6 & 10 & 6.3 & 0.03 \\
\hline Staph. Aureus & 17 & 5.4 & 13 & 8.4 & 4 & 2.5 & 0.02 \\
\hline Strep. Uberis & 30 & 9.6 & 12 & 7.8 & 18 & 11.3 & 0.33 \\
\hline Strep. Dysgalactiae & 10 & 3.2 & 7 & 4.6 & 3 & 1.9 & 0.21 \\
\hline C. bovis & 14 & 4.5 & 0 & 0.0 & 14 & 8.8 & $<0.01$ \\
\hline Other streptococci & 3 & 1.0 & 2 & 1.3 & 1 & 0.6 & 0.62 \\
\hline Gram negative bacteria & 4 & 1.2 & 3 & 2.0 & 1 & 0.6 & 0.74 \\
\hline Total & 313 & 100.0 & 159 & 100.0 & 154 & 100.0 & \\
\hline
\end{tabular}

${ }^{\mathrm{a}}$ Comparisons of specified bacteria between HIGH and NORM.

resistance to all antibiotics in the NORM group (62.5\%) was higher than that of the HIGH one (23.1\%). Interestingly, two isolates were resistant to vancomycin in the HIGH group.

Bacterial isolates from quarter milk samples of subclinical mastitis cows were separated into farm groups as shown in Table 3. Overall, most isolates were environmental streptococci (13.8\%), including Strep. uberis (9.6\%), Strep. dysgalactiae (3.2\%), and other streptococci (1.0\%). Other isolates showing high levels of intramammary infection were CNS (9.9\%), Staph. aureus (5.4\%), and C. bovis (4.5\%). Prevalence of CNS (13.6\%) and Strep. uberis (11.3\%) were at the highest level in the NORM and HIGH, respectively. In comparison between the two groups, the HIGH group had higher isolates of $C$. bovis $(p<0.05)$, but significantly lower isolates of CNS and Staph. aureus than the NORM group.

Percentages of antibiotic resistant patterns of mastitiscausing pathogens from farms with high and normal antibiotic use are shown in Table 4. Values of overall resistance indicate that Strep. uberis and Strep. dysgalactiae have high levels of resistance, especially to oxytetracycline, gentamycin and neomycin. In contrast, staphylococci were highly susceptible to oxytetracycline, gentamycin, or neomycin. The most susceptible antibiotic for all 4 mastitis pathogens were cephalexine and vancomycin. These results suggest that there were differences in the percentage of isolates that showed resistance to cloxacillin between NORM and HIGH use farms. Resistance percentages of CNS, Staph. aureus and Strep. uberis against cloxacillin were higher in the HIGH group than in the NORM one. However, no significant difference was found in any statistical tests among the 4 mastitis pathogens in the NORM or HIGH group.

Percentages of antibiotic resistant patterns of staphylococci and streptococci, both of which cause mastitis, from farms with high and normal antibiotic use are shown in Table 5. Staphylococci were highly resistant to cloxacillin $(28.6 \%)$ and oxacillin $(21.0 \%)$ in the HIGH group, and streptococci were highly resistant to oxytetracycline $(36.8 \%$ and $22.7 \%$ ), gentamycin $(73.7 \%$ and $77.3 \%)$ and neomycin (94.7\% and $90.9 \%)$ in the

Table 4. Percentages of antibiotic resistant patterns of pathogens causing mastitis in farms with excessive and normal antibiotic use

\begin{tabular}{|c|c|c|c|c|c|c|c|c|}
\hline \multirow[b]{2}{*}{ Antibiotics } & \multicolumn{2}{|c|}{ CNS } & \multicolumn{2}{|c|}{ Staph. aureus } & \multicolumn{2}{|c|}{ Strep. uberis } & \multicolumn{2}{|c|}{ Strep. dysgalactiae } \\
\hline & $\begin{array}{l}\text { NORM } \\
(\mathrm{n}=21)\end{array}$ & $\begin{array}{c}\text { HIGH } \\
(\mathrm{n}=11)\end{array}$ & $\begin{array}{l}\text { NORM } \\
(n=13)\end{array}$ & $\begin{array}{l}\mathrm{HIGH} \\
(\mathrm{n}=4)\end{array}$ & $\begin{array}{l}\text { NORM } \\
(n=12)\end{array}$ & $\begin{array}{c}\text { HIGH } \\
(\mathrm{n}=18)\end{array}$ & $\begin{array}{c}\text { NORM } \\
(n=7)\end{array}$ & $\begin{array}{l}\mathrm{HIGH} \\
(\mathrm{n}=3)\end{array}$ \\
\hline Oxytetracyclin & 4.8 & 10.0 & 30.8 & 0.0 & 25.0 & 16.7 & 50.0 & 66.7 \\
\hline Cloxacillin & $4.8 *$ & $10.0^{*}$ & $15.4 *$ & $25.0 *$ & $8.3 *$ & $22.2 *$ & 0.0 & 0.0 \\
\hline Oxacillin & 9.5 & 20.0 & 0.0 & 25.0 & 0.0 & 16.7 & 0.0 & 0.0 \\
\hline Cephalexine & 0.0 & 0.0 & 0.0 & 0.0 & 0.0 & 5.6 & 0.0 & 0.0 \\
\hline Vancomycin & 4.8 & 0.0 & 0.0 & 0.0 & 0.0 & 0.0 & 0.0 & 0.0 \\
\hline Gentamycin & 0.0 & 0.0 & 0.0 & 0.0 & 75.0 & 72.2 & 66.7 & 100.0 \\
\hline Erythromycin & 9.5 & 0.0 & 0.0 & 0.0 & 0.0 & 5.6 & 0.0 & 0.0 \\
\hline Neomycin & 0.0 & 10.0 & 0.0 & 0.0 & 91.7 & 77.8 & 100.0 & 100.0 \\
\hline All antibiotics ${ }^{\mathrm{a}}$ & 23.8 & 45.5 & 38.5 & 25.0 & 91.7 & 88.9 & 100.0 & 100.0 \\
\hline Resistances $\geq 2$ antibiotics & 4.8 & 18.2 & 0.0 & 0.0 & 25.0 & 22.2 & 28.6 & 66.7 \\
\hline
\end{tabular}

${ }^{a}$ Resistant to at least one drug test. * Comparisons of specified bacteria between HIGH and NORM. 
Table 5. Percentages of antibiotic resistant patterns of staphylococci and streptococci, which both cause mastitis in farms with high and normal antibiotic use

\begin{tabular}{|c|c|c|c|c|c|c|}
\hline \multirow[b]{2}{*}{ Antibiotics } & \multicolumn{2}{|c|}{ Staphylococci } & \multicolumn{2}{|c|}{ Streptococci ${ }^{\mathrm{a}}$} & \multicolumn{2}{|c|}{ Both pathogens ${ }^{b}$} \\
\hline & $\begin{array}{l}\text { NORM } \\
(\mathrm{n}=34)\end{array}$ & $\begin{array}{l}\text { HIGH } \\
(\mathrm{n}=15)\end{array}$ & $\begin{array}{l}\text { NORM } \\
(\mathrm{n}=19)\end{array}$ & $\begin{array}{c}\text { HIGH } \\
(\mathrm{n}=22)\end{array}$ & $\begin{array}{l}\text { NORM } \\
(\mathrm{n}=55)\end{array}$ & $\begin{array}{l}\text { HIGH } \\
(\mathrm{n}=37)\end{array}$ \\
\hline Oxytetracyclin & 14.7 & 7.1 & 36.8 & 22.7 & 21.8 & 16.2 \\
\hline Cloxacillin & 14.7 & 28.6 & 5.3 & 22.7 & $10.9 * *$ & $27.0 * *$ \\
\hline Oxacillin & $5.9^{*}$ & $21.0 *$ & 0.0 & 13.6 & $3.6^{* *}$ & $18.9 * *$ \\
\hline Cephalexine & 2.9 & 7.1 & 0.0 & 4.5 & 1.8 & 5.4 \\
\hline Vancomycin & 2.9 & 0.0 & 0.0 & 0.0 & 1.8 & 0.0 \\
\hline Gentamycin & 0.0 & 0.0 & 73.7 & 77.3 & $27.3^{*}$ & $45.9^{*}$ \\
\hline Erythromycin & 5.9 & 0.0 & 0.0 & 4.5 & 3.6 & 2.7 \\
\hline Neomycin & 0.0 & 7.1 & 94.7 & 81.8 & $34.5^{*}$ & $51.3^{*}$ \\
\hline All antibiotics ${ }^{c}$ & 29.4 & 40.0 & 94.7 & 90.9 & $52.7 *$ & $69.4^{*}$ \\
\hline Resistance $\geq 2$ antibiotics & 2.9 & 13.3 & 26.3 & 31.8 & 10.9 & 22.2 \\
\hline
\end{tabular}

${ }^{\text {a }}$ Streptococci including Strep. uberis, Strep. dysgalactia, and other streptococci. ${ }^{\mathrm{b}}$ Pathogens including both staphylococci and streptococci

${ }^{\mathrm{c}}$ Resistant to at least one drug test.* Differences between NORM and HIGH at $\mathrm{p}<0.05$. ** Differences between NORM and HIGH at $\mathrm{p}<0.05$.

NORM and HIGH group, respectively. Both staphylococci and streptococci were highly resistant to cloxacillin and oxacillin in the HIGH group. Most mastitis pathogens were susceptible to cephalexine, vancomycin and erythromycin. The percentage of antibiotic resistance for staphylococci against oxacillin in the NORM group was lower than that in the HIGH one. In comparison between pathogens of the HIGH and NORM group, antibiotic resistance against cloxacillin and oxacillin was associated with the frequency of antibiotic use in farms $(\mathrm{p}<0.05)$. Gentamycin, neomycin and all antibiotics in the HIGH group tended to have higher resistant percentages than in the NORM group.

\section{DISCUSSION}

In this study, farms were separated into two groups: normal use (NORM), being no more than 2 times/cow/yr of antibiotic use, and excessive use (HIGH), being more than 2 times/cow/yr. Based on a report from Thai Drug Control Division, the number of animal drugs produced in Thailand increased 3.9 times between 1996 and 2005 (Thai-DrugControl-Division, 2009). One of the food-safety issues in Thailand is misuse or over-use of antibiotics, which sometimes leaves drug residuals in meat and dairy products (Ranong and Chalermpao, 2003). Based on two consecutive SCC measurements, subclinical mastitis prevalence in the NORM group (0.43) was higher than that of the HIGH group (0.35) during the last 3 months prior study. The prevalence in this study was a little higher than that previously reported in Thailand (Chaikhun et al., 2005), and Ethiopia (Workineh et al., 2002; Almaw et al., 2008). Farms with high limitations on antibiotic use, especially organic farms, have a higher prevalence of subclinical mastitis than conventional farms (Roesch et al., 2007). A study conducted in Denmark provided strong evidence that the rate of mastitis therapy was associated with a desire to reduce overall antibiotic treatment.

Public health concerns advise prudent use of antibiotics, as their use may promote bacterial antibiotic resistance and leave antibiotic residues in the food chain (Berry and Hillerton, 2002). To reduce the risk of getting diseases from antibiotic resistant bacteria, the use of antibiotics must be restricted. In this study, Bacillus spp. and CNS were used as bacterial normal flora in a dairy farm environment. Bacillus spp., including B. cereus and B. anthracis, were chosen as a representative for Gram-positive indigenous soil bacteria to test the effect of spreading to various environments in many studies (Jensen et al., 2001; Black et al., 2008). CNS was also used for investigating environment such as wastewater and drinking water (Faria et al., 2009). The percentages of Bacillus spp. resistance to all antibiotics in the NORM group were significantly lower than those of the HIGH group; whereas, the percentage of CNS resistance to all antibiotics the NORM group was higher than that of the HIGH one. Antibiotic resistant environmental bacteria, shown in this study, might relate to the high use of antibiotics in smallholder dairy farms in Thailand. In addition, vancomycin resistant bacteria were found in the HIGH group. The high use of antibiotic may participate in high frequency of improper antibiotic use resulting in increasing a frequency of antibiotic resistance (McAllister et al., 2001). In addition a conventional small dairy farm had lower antibiotic resistance after managing as an experimentally organic dairy farm for 6 month (Suriyasathaporn, 2010).

This study showed a similar result to a previous one in Chiang Mai Province, Thailand, in which most bacterial isolates were environmental streptococci and CNS (Boonyayatra et al., 2007; Suriyasathaporn, 2011). Regarding to antibiotic using, both CNS and Strep. uberis 
were the most common isolates in the NORM and HIGH group, respectively. However, CNS is a member of the opportunistic pathogen group, which mostly causes subclinical mastitis and is, reported less on the problems of antibiotic resistance (Boonyayatra et al., 2007). Interestingly, $C$. bovis was isolated less in the NORM group than in the HIGH one $(\mathrm{p}<0.05)$. C. bovis is contagious mastitis-causing bacteria that are most commonly associated with subclinical infection. Intramammary infection of $C$. bovis not only causes moderately increasing SCC, but also mildly increasing California Mastitis Test or CMT score (Radostits et al., 2008). C. bovis might be related to fewer mastitis diagnoses, and is consequently found in the HIGH group.

Values of overall resistance indicate that Strep. uberis and Strep. dysgalactiae have high resistance levels, especially to oxytetracycline, gentamycin and neomycin (Table 4). In contrast, staphylococci are highly susceptible to oxytetracycline, gentamycin, or neomycin. All 4 mastitis pathogens were most susceptible to cephalexine and vancomycin. In general, resistant isolates were distinguished by the difference of their minimal inhibitory concentration (MIC). Pol and Ruegg (2007) showed higher MIC levels of most antibiotics versus environmental streptococci than those found in CNS. In most antibiotic use in smallholder dairy farms, cloxacillin showed differences in percentages of antibiotic resistance between farms that used normal and high antibiotics. Percentages of CNS, Staph. aureus and Strep. uberis resistance against cloxacillin in the HIGH group were higher than those in the NORM one.

In northern Thailand, cloxacillin represents over $80 \%$ of the intramammary drugs available on the market. A wide variety of antibiotic drugs has been used, often in an indiscriminate and inappropriate manner, thus impairing solutions to problems or leading to aggravation. Moreover, an important problem that arises from this kind of conduct is the increasing occurrence of microbial resistance (Susamo and Ocampo, 1992). Furthermore, the wide use of sulfa-trimethroprim, tetracycline and gentamicin to treat gastro-intestinal and other diseases in cattle has probably aided in developing resistance to these antibiotic agents.

Cloxacillin is the antibiotic mostly used in Thailand's dairy farms and it showed differences in percentages of antibiotic resistance between the NORM and HIGH group. The percentages of CNS, Staph. aureus and Strep. uberis resistance to cloxacillin in the HIGH group were higher than those in the NORM group. However, no significant difference was found among the 4 mastitis pathogens in all statistical tests between the NORM and HIGH group. The lower usage of antibiotics in the NORM group might be related to lower resistance levels. A previous study showed a close relationship between levels of antibiotic resistance and the exposition of antibiotic use (Lopez-Lozano et al., 2000)

\section{CONCLUSION}

In conclusion, farms with excessive use of antibiotics had a lower prevalence of mastitis. Mastitis-causing bacteria occurring in farms with excessive use and normal use of antibiotics were environmental streptococci and coagulase negative staphylococci, respectively. The problem of antibiotic resistance was found more in farms with excessive antibiotic usage than those with normal usage.

\section{ACKNOWLEDGEMENTS}

We would like to express our sincere thanks to farmers in Mae Wang dairy cooperative who gave us an opportunity for the study. This study was funded by Thailand Research Fund in fulfillment of the project. The authors also thank Rudland R. Colin for his English checking.

\section{REFERENCES}

Almaw, G., A. Zerihun and Y. Asfaw. 2008. Bovine mastitis and its association with selected risk factors in smallholder dairy farms in and around bahir dar, ethiopia. Trop. Anim. Health Prod. 40:427-432.

Berry, E. A. and J. E. Hillerton. 2002. The effect of selective dry cow treatment on new intramammary infections. J. Dairy Sci. $85: 112-121$.

Black, D. G., T. M. Taylor, H. J. Kerr, S. Padhi, T. J. Montville and P. M. Davidson. 2008. Decontamination of fluid milk containing bacillus spores using commercial household products. J. Food Prot. 71:473-478.

Boonmar, S., A. Bangtrakulnonth, S. Pornruangwong, S. Samosornsuk, K. Kaneko and M. Ogawa. 1998. Significant increase in antibiotic resistance of salmonella isolates from human beings and chicken meat in thailand. Vet. Microbiol. 62:73-80.

Boonyayatra, S., J. Thaboonpeng, K. Kreausukon and W. Suriyasathaporn. 2007. Anitimicrobial resistance of mastitisassociated bacteria in lactating dairy cows in chiang mai province. Chiang Mai Vet. J. 5:135-145.

Chaikhun, T., S. Surawong, S. Boonyayatra and W. Suriyasathaporn. 2005. Factors associated with subclinical mastitis in posparturient lactating cows in chiang mai and lumphun provinces. Chiang Mai Vet. J. 3:31-42.

Chantalakhana, C. and P. Skunmun. 2002. Sustainable smallholder animal systems in the tropics. Kasetsart University Press, Bangkok.

Faria, C., I. Vaz-Moreira, E. Serapicos, O. C. Nunes and C. M. Manaia. 2009. Antibiotic resistance in coagulase negative staphylococci isolated from wastewater and drinking water. Sci. Total Environ. 407:3876-3882.

Hanson, R., J. B. Kaneene, P. Padungtod, K. Hirokawa and C. 
Zeno. 2002. Prevalence of salmonella and e. Coli, and their resistance to antimicrobial agents, in farming communities in northern thailand. Southeast Asian J. Trop. Med. Publ. Health. 33:120-126.

Harmon, R. J., R. J. Eberhart, D. E. Jasper, B. E. Langlois and R. A. Wilson. 1990. Microbiological procedures for the diagnosis of bovine udder infection. 3rd Ed. National Mastitis Council Inc., Arlington, VA.

Isenbarger, D. W., C. W. Hoge, A. Srijan, C. Pitarangsi, N. Vithayasai, L. Bodhidatta, K. W. Hickey and P. D. Cam. 2002. Comparative antibiotic resistance of diarrheal pathogens from vietnam and thailand, 1996-1999. Emerg. Infect. Dis. 8:175180.

Jensen, L. B., S. Baloda, M. Boye and F. M. Aarestrup. 2001. Antimicrobial resistance among pseudomonas spp. and the bacillus cereus group isolated from danish agricultural soil. Environ. Int. 26:581-587.

Lopez-Lozano, J. M., D. L. Monnet, A. Yague, A. Burgos, N. Gonzalo, P. Campillos and M. Saez. 2000. Modelling and forecasting antimicrobial resistance and its dynamic relationship to antimicrobial use: A time series analysis. Int. J. Antimicrob. Agents 14:21-31.

McAllister, T. A., L. J. Yanke, G. D. Inglis and M. E. Olson. 2001. Is antibiotic use in dairy cattle causing antibiotic resistance? Adv. Dairy Technol. 13:229-247.

Moran, J. 2009. Business management for tropical dairy farmers. Landlinks Press, Collingwood, Victoria.

National Committee for Clinical Laboratory Standards (NCCLS) 2002. Performance Standards for Antimicrobial Disk and Dilution Susceptibility Tests for Bacteria Isolated from Animals; Approved standard M31-A2. National Committee for Clinical Laboratory Standards, Wayne, PA.
National Mastitis Council (NMC). 1999. Laboratory handbook on bovine mastitis. NMC Inc., Madison.

Pol, M. and P. L. Ruegg. 2007. Relationship between antimicrobial drug usage and antimicrobial susceptibility of gram-positive mastitis pathogens. J. Dairy Sci. 90:262-273.

Radostits, O. M., C. C. Gay, K. W. Hinchcliff and P. D. Constable. 2008. Veterinary medicine; a textbook of the diseases of cattle, horses, sheep, pigs and goats. WB. Sauders, Philadelphia.

Ranong, V. N. and N. Chalermpao. 2003. Environmental, health, and welfare issues on thai livestock sector. In: Project on Livestock Industrialization, Trade and Social-HealthEnvironment. FAO, Agriculture and Consumer Protection.

Roesch, M., M. D. Doherr, W. Scharen, M. Schallibaum and J. W. Blum. 2007. Subclinical mastitis in dairy cows in swiss organic and conventional production systems. J. Dairy Res. 74:86-92.

Susamo, H. and L. Ocampo. 1992. Pharmacological basis for treatment of bovine mastitis-review. Int. J. Vet. Med. 47:127135.

Suriyasathaporn, W. 2010. Milk quality and antimicrobial resistance against mastitis pathogens after changing from a conventional to an experimentally organic farm. Asian-Aust. J. Anim. Sci. 23:659-664.

Suriyasathaporn, W. 2011. Epidemiology of subclinical mastitis and their antibacterial susceptibility in smallholder dairy farms, Chiang Mai provinces, Thailand. J. Anim. Vet. Adv. 10:316321.

Thai-Drug-Control-Division. 2009. Amounts of modern drug produced in thailand. http://www.app1.fda.moph.go.th/drug/ zone_search/files/sea001_001.asp

Workineh, S., M. Bayleyegn, H. Mekonnen and L. N. D. Potgieter. 2002. Prevalence and aetiology of mastitis in cows from two major ethiopian dairies. Trop. Anim. Health Prod. 34:19-25. 